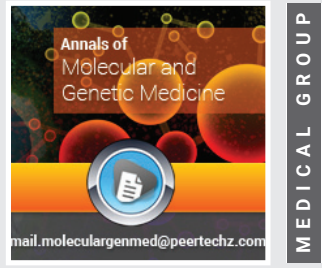

\section{A summary of the molecular testing recommended in acute myeloid leukemia}

\author{
Ruth Stuckey ${ }^{1}$, Cristina Bilbao-Sieyro ${ }^{1,2}$ and María Teresa \\ Gómez-Casares ${ }^{1,3 *}$ \\ ${ }^{1}$ Hematology Department, Hospital Universitario de Gran Canaria Dr. Negrín, 35019 Las Palmas de \\ Gran Canaria, Spain. \\ ${ }^{2}$ Morphology Department, Universidad de Las Palmas de Gran Canaria, 35016 Las Palmas de Gran \\ Canaria, Spain \\ ${ }^{3}$ Department of Medical Sciences, Universidad de Las Palmas de Gran Canaria, 35016 Las Palmas de \\ Gran Canaria, Spain
}

Received: 01 April, 2020

Accepted: 17 April, 2020

Published: 18 April, 2020

*Corresponding author: Dr. María Teresa GómezCasares, MD, PhD, Hematology Department, Hospital Universitario de Gran Canaria Dr. Negrín, 35019 Las Palmas de Gran Canaria, Spain, Tel: +34 928 479433; E-mail:mgomcasf@gobiernodecanarias.org

Keywords: Acute myeloid leukemia; Next-generation sequencing; Diagnosis; Prognosis; Risk stratification; Targeted therapies; Somatic mutations; Germline mutations; Personalized medicine

\section{https://www.peertechz.com}

Check for updates

\title{
Abstract
}

Advances in Next-Generation Sequencing technologies (NGS) are revealing germline and somatic mutations that, together with karyotype, determine the diagnosis and subtype of Acute Myeloid Leukemia (AML). Molecular testing is also essential for the genetic risk stratification of patients with AML, in particular for those with normal karyotype AML (CN-AML), a large and highly heterogeneous group of patients. Patients determined to be at high risk could benefit from a more aggressive first-line therapy, or a more directed therapy, such as midostaurin (for FLT3-mutated AML) or ivosidenib (for IDH1-mutated AML). Here, we will summarize the molecular testing currently recommended in AML and introduce new mutations that may have prognostic value and clinical application in the near future.

\section{Introduction}

Acute Myeloid Leukemia (AML) is a complex hematological neoplasm, characterized by the World Health Organization (WHO) into multiple subtypes [1,2]. Cytogenetic analysis is essential for AML diagnosis since certain subtypes are characterized by numerical chromosome abnormalities or gross translocations, including loss of chromosome 5 or the common structural aberration $\mathrm{t}(8 ; 21)$ (q22;q22), leading to production of the AML-ETO fusion gene, respectively. In fact, according to the National Comprehensive Cancer Network (NCCN), "karyotype represents the single most important prognostic factor for predicting remission rates, relapse risks and overall survival outcomes" [3].

In recent years, significant progress has been made in the biological understanding of AML [4]. In particular, as a result of advances in Next-Generation Sequencing technologies (NGS), genetic studies are revealing an ever-rising number of somatic mutations that help to determine both the phenotypic and prognostic heterogeneity of this pathology [5].

The increasingly widespread use of NGS technology with gene panels in clinics means that the simultaneous analysis of mutations in a high number of genes is both practical and economically feasible [5]. Moreover, the incorporation of molecular markers into current prognostic algorithms is permitting the more precise risk stratification of patients. Indeed, the European Leukemia Net (ELN) currently recommends the evaluation of mutations by NGS using a panel of genes commonly mutated in AML (or a generic myeloid neoplasm gene panel) at diagnosis and at relapse to inform the clinical management of patients with AML [6].

This review will summarize the mutations that currently serve as molecular markers of AML as well as introduce those that may have informative value in the diagnosis, risk stratification and follow-up of patients with AML in the near future. 


\section{Genetic testing recommended in AML}

\section{To inform diagnosis}

Advances in NGS technologies have driven the inclusion of several new AML subtypes according to their associated genetic alterations, highlighting the importance of molecular testing for a complete diagnosis. For instance, the WHO included the categories of "AML with mutated NPM1" and "AML with biallelic mutations of CEBPA" in 2008 [1], and "AML with mutated RUNX1" and "AML with BCR-ABL1" were provisionally recognized as new entities in the 2016 revision [2]. Although the latter entity is not frequent (less than $1 \%$ of all AML cases $[7,8])$, de novo AML patients identified as having this subtype may benefit from treatment with tyrosine kinase inhibitors $[9,10]$.

\section{Germline mutations}

The presence of germline mutations in several genes have been shown to cause a predisposition to myeloid neoplasms, including AML. These observations led to the inclusion of a new category of myeloid neoplasms with germline predisposition (Table 1) in the 2016 revision of the WHO classification of hematological neoplasms [2].

Table 1: Classification of myeloid neoplasms with germline predisposition. Adapted from [2].

With pre-existing platelet disorders and With other organ dysfunction.

AML with CEBPA germline mutation

Myeloid neoplasms with germline mutation of DDX41

With pre-existing platelet disorders

Myeloid neoplasms with germline mutation of RUNX1

Myeloid neoplasms with germline mutation of ANKRD26

Myeloid neoplasms with germline mutation of ETV6

With other organ dysfunction

Myeloid neoplasms with germline mutation of GATA2

Myeloid neoplasms associated with bone marrow failure syndromes

Myeloid neoplasms associated with telomere biology disorders

Juvenile myelomonocytic leucemia associated with neurofibromatosis, Noonan syndrome or Noonan-syndrome like disorders

Myeloid neoplasms associated with Noonan syndrome

Myeloid neoplasms associated with Down syndrome

When there is a suspicion that a patient may harbor congenital AML-due to a family history of neoplasia, an exceptionally early age of AML presentation, or the presence of various tumors-the ELN recommends the genetic analysis of the genes RUNX1, CEBPA, GATA2, DDX41, ANKRD26, and ETV6 [6]. Mutations in these genes are just some that bestow a predisposition to the development of AML; others include mutations in genes associated with a general susceptibility to cancer, such as the Fanconi anemia genes, or TP 53 and BRCA1/ $B R C A 2[6,11-13]$, often mutated in therapy-related leukemias [12].

The analysis of germline mutations is critical to inform the selection of a suitable donor if the patient is a candidate for Hematopoietic Stem Cell Transplantation (HSCT). Germline mutations can also confer a higher risk of relapse in AML or a predisposition to the development of a secondary leukemia, including therapy-related leukemias [12]. For example, between $5 \%$ and $7 \%$ of patients with CEBPA-mutated AML harbor germline mutations [13] and although the majority reach complete remission following chemotherapy, recurrent disease is frequent [13].

If a positive result is detected, it is recommended that genetic counseling be offered to the patient's family members for the prevention and/or early detection of germline myeloid neoplasms [11].

\section{The importance of studying TP53}

In the case of $\mathrm{TP}_{53}$, the study of mutations in this gene is of particular importance given that their presence predicts a particularly poor outcome for the patient $[4,14,15]$. Mutations in the TP53 gene locus may be point mutations or deletions of 17 p13 of a range of sizes, and either somatic or germline [16].

TP53 mutations usually coincide with a complex karyotype $[14,15]$. However, their presence in conjunction with a monosomal karyotype or aneuplodies such as-5/5q and -7/7q-themselves associated with high risk-is independent and additive in terms of risk stratification, giving rise to an extremely adverse prognosis $[4,15]$.

Recently, the presence of ASXL1 and RUNX1 mutations were also included in the high-risk category of AML due to their association with a worse prognosis and poor survival, respectively [2]. Germline mutations of the latter are associated with familial platelet disorder with associated myeloid malignancy, a disorder of abnormal hematopoiesis that confers affected individuals with a higher risk of AML [17]. Moreover, germline mutations in ASXL1 [18], have been reported as causing a predisposition to myelodysplastic syndrome and/ or AML. However, further studies are required to confirm the impact of germline mutations in ASXL1, as well as other germline mutations such as $S R P 72$ [19], and CBFA2 [20] before their possible inclusion in congenital AML genetic testing recommendations in the future.

\section{Risk stratification}

The genetic risk stratification of patients with AML is especially useful to determine the response to therapy of patients with normal karyotype AML (CN-AML), a particularly heterogeneous group of patients representing $40 \%-50 \%$ of all new cases.

\section{Analysis of FLT3 mutations}

The analysis of mutations in the Fms-Like Tyrosine kinase 3 gene (FLT3), including Internal Tandem Duplications (ITD) and mutations in the Tyrosine Kinase Domain (TKD), is recommended by the WHO, NCCN and ELN for patients with $\mathrm{CN}-\mathrm{AML}$ due to its prognostic value $[2,3,6]$. Specifically, numerous studies have reported higher relapse rates and worse 
overall survival after chemotherapy for patients with FLT3-ITD $[21,22]$. On the other hand, the prognostic impact of FLT3-TKD mutations is not as well defined.

Mutations in FLT3 are identified in approximately a third of de novo AML cases and are common in many AML subtypes. Such mutations frequently co-exist with mutations in exon 12 of NPM1, detected in approximately $30 \%$ of adults aged up to 65 years with AML, and reaching up to $50 \%$ in patients with $\mathrm{CN}$ AML [23], with FLT3-ITD mutations present in $40 \%$ of cases. For example, FLT3 mutations often coexist with chromatinspliceosome-mutated AML, accounting for $13 \%$ of AML cases (FLT3-ITD mutations present in 15\%); PML-RARA AML ( $\mathrm{t}(15 ; 17)(\mathrm{q} 22 ; \mathrm{q} 21)$, accounting for $13 \% \cdot$ of AML cases (FLT3-ITD mutations present in 35\% and FLT3-TKD mutations present in 15\%); CBFB-MYH11 AML (inv(16)(p13.1q22)), accounting for $7 \%$ of AML cases (FLT3-TKD mutations present in 20\%), and DEKNUP214 AML (t6;9)(p23;q34.1), accounting for 1\% of AML cases (FLT3-ITD mutations present in 70\%) [6].

The co-existence of FLT3 mutations has a significant impact on the prognosis of patients with normal karyotype, differentiating the NPM1-mutated subgroup into patients with wild-type $\mathrm{FLT}_{3}$, of favorable prognosis, from patients with FLT3-ITD, of intermediate prognosis (Table 2). Likewise, patients with FLT3-ITD without an NPM1 mutation have a higher estimated risk of relapse following chemotherapy and are normally considered as candidates for HSCT [6,21-25].

Table 2: Genetic risk stratification according to the NCCN and ELN guidelines. Adapted from $[3,6]$

\begin{tabular}{|c|c|c|}
\hline Risk & Cytogenetics & Molecular abnormalities \\
\hline Favorable & $\begin{array}{c}\text { CBF: } \\
\text { inv(16) or } \mathrm{t}(16 ; 16) ; C B F B- \\
M Y H 11 \\
\mathrm{t}(8 ; 21) \text { or } \mathrm{t}(15 ; 17) ; \text { RUNX1- } \\
\text { RUNX1T1 }\end{array}$ & $\begin{array}{c}\text { Normal cytogenetics: } \\
\text { Mutated NPM1 without FLT3-ITD or } \\
\text { FLT3-ITD lowt } \\
\text { or biallelic CEBPA mutation }\end{array}$ \\
\hline Intermediate & $\begin{array}{c}\text { Normal cytogenetics: } \\
\mathrm{t}(9 ; 11) ; \text { MLLT3-KMT2A } \\
\mathrm{t}(8 ; 21), \operatorname{inv}(16), \mathrm{t}(16 ; 16) \\
\text { No other defined } \\
\text { abnormality }\end{array}$ & $\begin{array}{l}\text { CBF with c-KIT mutation } \\
\text { NPM1 mutated with FLT3-ITD } \\
\text { NPM1 } 1 \text { wild-type without FLT3-ITD or } \\
\text { with FLT3-ITD } \\
\text { gent (without adverse } \\
\text { getic lesions) }\end{array}$ \\
\hline Adverse & $\begin{array}{c}\text { Complex* or monosomal } \\
\text { karyotype } \\
-5,-5 \mathrm{q},-7,-7 \mathrm{q} \\
\mathrm{t}(\mathrm{v} ; 11 \mathrm{q} 23.3) ; \text { reordered } \\
\text { KMT2A } \\
\text { inv(3) or } \mathrm{t}(3 ; 3) ; \text { GATA2, } \\
\text { MECOM(EVI1) } \\
\mathrm{t}(6 ; 9) ; \text { DEK-NUP214 } \\
\mathrm{t}(9 ; 22) ; \text { BCR-ABL1 }\end{array}$ & $\begin{array}{l}\text { Normal cytogenetics: } \\
\text { NPM1 wild-type with FLT3-ITD hight } \\
\text { TP53 mutated } \\
\text { RUNX1 mutated } \\
\text { ASXL1 mutated }\end{array}$ \\
\hline
\end{tabular}

CBF: Core Binding Factor; ITD: Internal Tandem Duplications; †: high allelic ratio $\geq 0.5$, low allelic ratio $<0.5 ; *: \geq 3$ chromosomal abnormalities

Finally, the identification of the molecular alterations that underlie AML is leading to the development of novel directed therapies. This is the case for midostaurin, a multikinase inhibitor, approved by the European Medicines Agency (EMA) and Food and Drug Administration (FDA) in combination with chemotherapy for the first-line treatment of adults with FLT3mutated AML [26]. Another second-generation Tyrosine Kinase
Inhibitor (TKI) gilteritinib has also been approved by the FDA for the treatment of relapsed or refractory FLT3-mutated AML [27].

Despite this, a 2017 survey carried out among AML experts in Europe and the United States reported that only $51.4 \%$ of specialists evaluate FLT3-ITD in all patients [28]; while at the national level, a recent survey among AML experts in Spanish clinics revealed that $7.5 \%$ "never" or "sometimes" carried out the analysis of FLT3 mutations [29]. These data demonstrate that there is still a lack of understanding of the prognostic and therapeutic indications of the presence of FLT3 mutations.

\section{Molecular analysis for risk stratification}

Since 2017, both the NCCN and the ELN recommend the routine detection of mutations in the genes CEBPA, NPM1 and RUNX1 at diagnosis to define the category of AML, as well as mutations in the genes KIT, FLT3 (ITD and TKD), NPM1, CEBPA, RUNX1, ASXL1 and TP53 (together with cytogenetic alterations) in order to refine to prognosis of patients with AML $[3,6,30]$.

In the case of core binding factor AML (CBF-AML), the presence of mutations in the KIT gene reduces the prognosis from favorable to intermediate risk [31]. Meanwhile, in the case of CN-AML, the presence of mutations in NPM1 and CEBPA (in the absence of FLT3-ITD mutations) improves the prognosis from intermediate risk to favorable, although the presence of FLT3-ITD mutations modifies the risk to adverse (Table 2) $[6,21-25]$. Specifically, FLT3-ITD with a high allelic ratio $(\geq 0.5)$ is associated with a poor prognosis (higher relapse rate and worse overall survival) [21-25]. However, AML patients mutated in NPM1 with a low FLT3-ITD allelic ratio (<0.5) have a similar prognosis to patients mutated in NPM1 without FLT3ITD; in other words, a favorable prognosis. [6,21-25].

It is important that mutational analysis is carried out promptly so that patients identified as high risk can benefit from a more aggressive first-line therapy, or a more directed therapy in some cases. For example, patients with a positive result for FLT3-ITD (with a ratio > 0.5) may be candidates for the addition of the TKI midostaurin to their chemotherapy regime or for HSCT.

\section{Patient follow-up}

\section{Relapsed and refractory AML}

In addition to its role in the accurate diagnosis of patients with AML, mutational analysis is also very informative in cases of relapsed or refractory AML. The repetition of mutational analysis (because a patient's profile of mutations may change over time or as the result of chemotherapy or other therapies) may identify possible targets against which there may be an approved directed treatment or an agent undergoing clinical trial. For example, gilteritinib, an inhibitor of FLT3 is approved to treat refractory AML or relapsed patients with mutated FLT3 [27].

Currently, there is a difference between the NCCN and ELN recommendations on molecular testing in AML. Specifically, in 
the 2017 update the ELN did not include a recommendation for the analysis of mutations in $I D H 1$ and $I D H 2$ in the evaluation of AML at diagnosis due to lack of evidence [6]. However, shortly after its publication, the FDA approved two directed therapies, ivosidenib (AG-120, Tibsovo ${ }^{\circledR}$ ) against IDH1-mutated AML andenasidenib (AG-221, IDHIFA ${ }^{\circledR}$ ) against $\mathrm{IDH}_{2}$-mutated AML $[32,33]$. Thus, in 2018 the NCCN included the recommendation for the analysis of mutations in the IDH1 and $I_{D H}$ genes because of the availability of FDA-approved directed therapies [30].

\section{Minimal residual disease MRD}

Minimal Residual Disease (MRD) has been shown to be a very important prognostic factor. High levels after chemotherapy are associated with relapse and so patients with a positive MRD are considered to be at risk [34]. The analysis of mutations, such as insertions and deletions in NPM1, permit their monitoring as a molecular marker of MRD [35]. The ELN's current recommendations describe the applicability of MRD testing for the follow-up of AML patients because it allows different therapeutic options to be optimized and personalized for patients with high MRD, such as an indication for HSCT or not [6].

\section{Future perspectives}

\section{Updating of risk stratification algorithms}

The list of mutations in genes with prognostic value is continually increasing. For example, studies have demonstrated that certain $M C M 7$ polymorphisms are associated with relapse and overall survival in AML patients [36], while the partial tandem duplication of $M L L$ ( $M L L$-PTD) confers worse prognosis to patients with CN-AML [37]. In the future it's probable that these or other genes could be incorporated into risk algorithms to help stratify patient subgroups, but only when sufficient evidence exists to support their prognostic value $[4,6,37]$.

\section{Prognostic relevance of mutations according to age}

Finally, another possible future modification to the NCCN and ELN's recommendations could be the inclusion of risk stratification algorithms not only optimized to the mutational profile of the patient but also to the patient's age.

In general, older patients with AML tend to have poorer results with standard chemotherapy regimens [38,39]. This could be caused by adverse karyotypes that are more common and/or the higher number of mutations in older patients with AML than younger patients with AML [4], although the association between the number of mutations and prognosis continues to be a matter of debate.

A phenomenon called clonal hematopoiesis of indeterminate potential (CHIP), which is intrinsic to aging, is characterized by the accumulation of mutations in the DNMT3A, TET2 and ASXL1 genes (collectively known as DTA mutations). A positive correlation exists between age and the presence of DTA mutations, even in healthy individuals [40,41], although studies have found an association between the accumulation of DTA mutations and a higher risk for developing myeloid neoplasms, including AML, as well as cardiovascular pathologies [40-42].
Nevertheless, the detection of DTA mutations in AML patients in remission is not associated with relapse [43].

It still remains to be determined whether the presence of different mutations in patients aged over 65 years of age has the same prognostic value as in patients aged under 65 years, although several groups are actively investigating this matter. For instance, preliminary data from the Alliance group indicates that mutations in the splicing factor $S F 1$ may refine the prognosis of NPM1-mutated AML patients aged over 60 years [44].

\section{Conclusion}

Molecular testing at diagnosis, remission and relapse can provide large amounts of data to guide the individualized clinical management of patients with AML. In addition, the analysis of mutations is particularly useful for informing the treatment choice.

The ELN recommends the evaluation of mutations in patients with AML at diagnosis and at relapse using NGS technology with gene panels, with which it's possible to analyze a high number of genes simultaneously and at an everdecreasing cost.

These panels generate more data than is currently recommended for the diagnosis and prognosis of patients with AML. However, with the continual advancements in our understanding of the impact of somatic mutations and the complex interactions between them, it may be possible to utilize this data in the future to optimize and personalize therapy for patients and in this way maximize their possibilities of reaching complete remission. As such, it is very important to store the samples of patients with AML in biobanks because, although the presence of a certain mutation is not prognostic in the current day, a new targeted therapy may be developed in the future.

\section{Acknowledgements}

Disclosure of potential conflicts of interest: No specific funding was received for the publication of this review. The authors have no conflicts of interest, commercial or otherwise, to declare.

\section{References}

1. Swerdlow S, Campo E, Harris NL, Jaffe ES, Pileri SA, et al. (2008) World Health Organization Classification of Tumours of Haematopoietic and Lymphoid Tissues. Update to $4^{\text {th }}$ Edition. Lyon, France: World Health Organization. Link: https://bit.ly/2z0C5LZ

2. Arber DA, Orazi A, Hasserjian R, Thiele J, Borowitz MJ, et al. (2016) The 2016 revision to the World Health Organization classification of myeloid neoplasms and acute leukemia. Blood 127: 2391-2405. Link: https://bit.ly/2Vfolx5

3. O'Donnell MR, Tallman MS, Abboud CN, Altman JK, Appelbaum FR, et al. (2017) Acute Myeloid Leukemia, Version 3.2017, NCCN Clinical Practice Guidelines in Oncology. J Natl Compr Canc Netw 15: 926-957. Link: https://bit.ly/3cnJwva

4. Papaemmanuil E, Gerstung M, Bullinger L, Gaidzik VI, Paschka P, et al. (2016) Genomic classification and prognosis in acute myeloid leukemia. N Engl J Med 374: 2209-2221. Link: https://bit.ly/2K93|KK

Citation: Stuckey R, Bilbao-Sieyro C, Gómez-Casares MT (2020) A summary of the molecular testing recommended in acute myeloid leukemia. Ann Mol Genet Med 4(1): 012-017. DOI: https://dx.doi.org/10.17352/amgm.000007 
5. Yang F, Anekpuritanang T, Press RD (2020) Clinical Utility of Next-Generation Sequencing in Acute Myeloid Leukemia. Mol Diagn Ther 24: 1-13. Link: https://bit.ly/2wM3YXz

6. Döhner H, Estey E, Grimwade D, Amadori S, Appelbaum FR, et al. (2017) Diagnosis and management of AML in adults: 2017 ELN recommendations from an international expert panel. Blood 129: 424-447. Link: https://bit.ly/2VdvgPQ

7. Keung YK, Beaty M, Powell BL, Molnar I, Buss D, et al. (2004) Philadelphia chromosome positive myelodysplastic syndrome and acute myeloid leukemia-retrospective study and review of literature. Leuk Res 28: 579-586. Link: https://bit.ly/3abFtRa

8. Konoplev S, Yin CC, Kornblau SM, Kantarjian HM, Konopleva M, et al (2013) Molecular characterization of de novo Philadelphia chromosomepositive acute myeloid leukemia. Leuk Lymphoma 54: 138-144. Link: https://bit.ly/34GUV6C

9. Ueda K, Horiike S, Zen K, Misawa S, Taniwaki M (2006) Complete cytogenetic and molecular response to treatment with imatinib mesylate for philadelphia chromosome positive acute myeloid leukemia with multilineage dysplasia. Leuk Lymphoma 47: 1967-1969. Link: https://bit.ly/3abFB36

10. Aoki J, Kakihana K, Kobayashi T, Hirashima Y, Akiyama H, et al. (2012) Tyrosine kinase inhibitor therapy for acute myeloid leukemia with lateappearing Philadelphia chromosome. Leuk Res 36: e41-e42. Link: https://bit.ly/2VDGITM

11. Suarez-González J, Andrés-Zayas C, Rodríguez-Macías G, Chicano $M$ Carbonell D, et al. (2018) Mutaciones genómicas germinales y susceptibilidad al desarrollo de leucemias. Asociación Español de Científicos, AEC. Link: https://bit.ly/2z1u2yu

12. Schulz E, Valentin A, Ulz P, Beham-Schmid C, Lind K, et al. (2012) Germline mutations in the DNA damage response genes BRCA1, BRCA2, BARD1 and TP53 in patients with therapy related myeloid neoplasms. J Med Genet 49 422-428. Link: https://bit.ly/3cnQJeL

13. Tawana K, Rio-Machin A, Preudhomme C, Fitzgibbon J (2017) Familial CEBPA-mutated acute myeloid leukemia. Semin Hematol 54: 87-93. Link: https://bit.ly/2xtcdbv

14. Haferlach C, Dicker F, Herholz H, Schnittger S, Kern W, et al. (2008) Mutations of the TP53 gene in acute myeloid leukemia are strongly associated with a complex aberrant karyotype. Leukemia 22: 1539-1541. Link: https://bit.ly/3cu06aT

15. Rucker FG, Schlenk RF, Bullinger L, Kayser S, Teleanu V, et al. (2012) TP53 alterations in acute myeloid leukemia with complex karyotype correlate with specific copy number alterations, monosomal karyotype, and dismal outcome. Blood 119: 2114-2121. Link: https://bit.ly/2ymA6kS

16. Zebisch A, Lal R, Müller M, Lind K, Kashofer K, et al. (2016) Acute myeloid leukemia with TP53 germ line mutations. Blood 128: 2270-2272. Link https://bit.ly/2wPr8fG

17. Latger-Cannard V, Philippe C, Bouquet A, Baccini V, Alessi MC, et al. (2016) Haematological spectrum and genotype-phenotype correlations in nine unrelated families with RUNX1 mutations from the French network on inherited platelet disorders. Orphanet J Rare Dis 11: 49. Link: https://bit.ly/2XJQYge

18. Seiter K, Htun K, Baskind P, Liu Z (2018) Acute myeloid leukemia in father and son with a germline mutation of ASXL1. Biomark Res 6: 7. Link: https://bit.ly/3ahm3Kw

19. Kirwan M, Walne AJ, Plagnol V, Velangi M, Ho A, et al. (2012) Exome sequencing identifies autosomal-dominant SRP72 mutations associated with familial aplasia and myelodysplasia. Am J Hum Genet 90: 888-892. Link: https://bit.ly/2KexCl8

20. Buijs A, Poddighe $P$, van Wijk R, van Solinge W, Borst E, et al. (2001) A novel CBFA2 single-nucleotide mutation in familial platelet disorder with propensity to develop myeloid malignancies. Blood 98: 2856-2858. Link: https://bit.ly/2VelVHF
21. Thiede C, Steudel C, Mohr B, Schaich M, Schäkel U, et al. (2002) Analysis of FLT3-activating mutations in 979 patients with acute myelogenous leukemia: association with $F A B$ subtypes and identification of subgroups with poor prognosis. Blood 99: 4326-4335. Link: https://bit.ly/3afrxFY

22. Pratcorona M, Brunet S, Nomdedéu J, Ribera JM, Tormo M, et al. (2013) Favorable outcome of patients with acute myeloid leukemia harboring a lowallelic burden FLT3-ITD mutation and concomitant NPM1 mutation: relevance to post-remission therapy.Blood 121: 2734-2738. Link: https://bit.ly/3coFZNe

23. Thiede C, Koch S, Creutzig E, Steudel C, Illmer T, et al. (2006) Prevalence and prognostic impact of NPM1 mutations in 1485 adult patients with acute myeloid leukemia (AML). Blood 107: 4011-4020. Link: https://bit.ly/2VB5PXx

24. Gale RE, Green C, Allen C, Mead AJ, Burnett AK, et al. (2008) Medical Research Council Adult ,Leukaemia Working Party. The impact of FLT3 internal tandem duplication mutant level, number, size, and interaction with NPM1 mutations in a large cohort of young adult patients with acute myeloid leukemia. Blood 111: 2776-2784. Link: https://bit.ly/2XEIxCR

25. Ho AD, Schetelig J, Bochtler T, Schaich M, Schäfer-Eckart K, et al. (2016) Allogeneic stem cell transplantation improves survival in patients with acute myeloid leukemia characterized by a high allelic ratio of mutant FLT3-ITD. Bio Blood Marrow Transplant 22: 462-469. Link: https://bit.ly/2VyE1mA

26. Stone RM, Mandrekar SJ, Sanford BL, Laumann K, Geyer S, et al. (2017) Midostaurin plus Chemotherapy for Acute Myeloid Leukemia with a FLT3 Mutation. N Engl J Med 377: 454-464. Link: https://bit.ly/2Kp904t

27. Perl AE, Altman JK, Cortes J, Smith C, Litzow M, et al. (2017) Selective inhibition of FLT3 by gilteritinib in relapsed or refractory acute myeloid leukaemia: a multicentre, first-in-human, open-label, phase 1-2 study. Lancet Oncol 18: 1061-1075. Link: https://bit.ly/2yi6a9z

28. George TI, Tworek JA, Thomas NE, Fatheree LA, Souers RJ, et al. (2017) Evaluation of testing of acute leukemia samples: survey result from the College of American Pathologists. Arch Pathol Lab Med 141: 1101-1106. Link: https://bit.ly/2KeJSbm

29. Gómez-Casares $M T$, de la Fuente Burguera $A$, Barragán $E$, Calasanz $M J$ Velasco JA, et al. (2019) Assessment of FLT3 mutation in acute myeloid leukemia: Results of a Spanish Delphi panel survey. HemaSphere 3: 803. Link: Link: https://bit.ly/2KdJZEo

30. National Comprehensive Cancer Network (NCCN) (2018) Acute Myeloid Leukemia, Version 1.2018, NCCN Clinical Practice Guidelines in Oncology. Link: https://bit.ly/34LgKIr

31. Jourdan E, Boissel N, Chevret S, Delabesse E, Renneville A, et al. (2013) Prospective evaluation of gene mutations and minimal residual disease in patients with core binding factor acute myeloid leukemia. Blood 121: 22132223. Link: https://bit.ly/2K9KTS8

32. DiNardo CD, Stein EM, de Bottom S, Roboz GJ, Altman JK, et al. (2018) Durable Remissions with Ivosidenib in IDH1-Mutated Relapsed or Refractory AML. N Engl J Med 378: 2386-2398. Link: https://bit.ly/2KdXWCO

33. Stein EM, DiNardo CD, Fathi AT, Pollyea DA, Stone RM, et al. (2019) Molecular remission and response patterns in patients with mutant-IDH2 acute myeloid leukemia treated with enasidenib. Blood 133: 676-687. Link: https://bit.ly/3bkrYjE

34. Ossenkoppele GJ, Schuurhuis GJ (2014) MRD in AML: it is time to change the definition of remission. Best Pract Res Clin Haematol 27: 265-271. Link: https://bit.ly/2VyFAks

35. Ivey A, Hills RK, Simpson MA, Jovanovic JV, Gilkes A, et al. (2016) Assessment of Minimal Residual Disease in Standard-Risk AML. N Engl J Med 374: 422 433. Link: https://bit.ly/3bjKWGX

36. Lee JS, Cheong HS, Koh Y, Ahn KS, Shin HD, et al. (2017) MCM7 polymorphisms associated with the AML relapse and overall survival. Ann. Hematol 96: 93-98. Link: https://bit.ly/2VeFv6w

Citation: Stuckey R, Bilbao-Sieyro C, Gómez-Casares MT (2020) A summary of the molecular testing recommended in acute myeloid leukemia. Ann Mol Genet Med 4(1): 012-017. DOI: https://dx.doi.org/10.17352/amgm.000007 
37. Patel JP, Gönen M, Figueroa ME, Fernandez H, Sun Z, et al. (2012) Prognostic relevance of integrated genetic profiling in acute myeloid leukemia. $\mathrm{N}$ Engl J Med 366: 1079-1089. Link: https://bit.ly/2VjOaF3

38. Büchner T, Berdel WE, Haferlach C, Haferlach T, Schnittger S, et al. (2009) Age-related risk profile and chemotherapy dose response in acute myeloid leukemia: a study by the German Acute Myeloid Leukemia Cooperative Group. J Clin Oncol 27: 61-69. Link: https://bit.ly/3cCaOOL

39. Kantarjian H, Ravandi F, O'Brien S, Cortes J, Faderl S, et al. (2010) Intensive chemotherapy does not benefit most older patients (age 70 years or older) with acute myeloid leukemia. Blood 116: 4422-4429. Link: https://bit.ly/2yrMKir

40. Genovese G, Kähler AK, Handsaker RE, Lindberg J, Rose SA, et al. (2014) Clonal hematopoiesis and blood-cancer risk inferred from blood DNA sequence. $\mathrm{N}$ Engl J Med 371: 2477-2487. Link: https://bit.ly/2RKZEiF

41. Jaiswal S, Fontanillas P, Flannick J, Manning A, Grauman PV, et al. (2014)
Age-related clonal hematopoiesis associated with adverse outcomes. N Engl J Med 371: 2488-2498. Link: https://bit.ly/3bj2Lpt

42. Jaiswal S, Natarajan P, Silver AJ, Gibson CJ, Bick AG, et al. (2017) Clona hematopoiesis and risk of atherosclerotic cardiovascular disease. $\mathrm{N}$ Engl $\mathrm{J}$ Med 377: 111-121. Link: https://bit.ly/2ymCYyl

43. Grimm J, Bill M, Jentzsch M, Beinicke S, Häntschel J, et al. (2019) Clinical impact of clonal hematopoiesis in acute myeloid leukemia patients receiving allogeneic transplantation. Bone Marrow Transpl 54: 1189-1197. Link: https://go.nature.com/3afus1d

44. Eisfeld AK, Kohlschmidt J, Mrózek K, Blachly JS, Walker CJ, et al. (2018) Mutation patterns identify adult patients with de novo acute myeloid leukemia aged 60 years or older who respond favorably to standard chemotherapy: an analysis of Alliance studies. Leukemia 32: 1338-1348. Link: https://bit.ly/2KbOyiv

\section{Discover a bigger Impact and Visibility of your article publication with}

Peertechz Publications

\section{Highlights}

* Signatory publisher of ORCID

* Signatory Publisher of DORA (San Francisco Declaration on Research Assessment)

* Articles archived in worlds' renowned service providers such as Portico, CNKI, AGRIS, TDNet, Base (Bielefeld University Library), CrossRef, Scilit, J-Gate etc.

* Journals indexed in ICMJE, SHERPA/ROMEO, Google Scholar etc.

* OAI-PMH (Open Archives Initiative Protocol for Metadata Harvesting)

* Dedicated Editorial Board for every journal

* Accurate and rapid peer-review process

* Increased citations of published articles through promotions

* Reduced timeline for article publication

Submit your articles and experience a new surge in publication services (https://www.peertechz.com/submission).

Peertechz journals wishes everlasting success in your every endeavours.

Copyright: @ 2020 Stuckey R, et al. This is an open-access article distributed under the terms of the Creative Commons Attribution License, which permits unrestricted use distribution, and reproduction in any medium, provided the original author and source are credited.

Citation: Stuckey R, Bilbao-Sieyro C, Gómez-Casares MT (2020) A summary of the molecular testing recommended in acute myeloid leukemia. Ann Mol Genet Med 4(1): 012-017. DOI: https://dx.doi.org/10.17352/amgm.000007 